\title{
Digital mapping of solonchak complexes using Sentinel-2A data
}

\author{
Azamat Suleymanov ${ }^{1, *}$, Ilyusya Gabbasova ${ }^{1}$, and Mikhail Komissarov ${ }^{1}$ \\ ${ }^{1}$ Ufa Institute of Biology, Ufa Federal Research Centre, Russian Academy of Sciences 450054, \\ Prospekt Octyabrya, 69, Ufa, Russia
}

\begin{abstract}
Land salinization is an up-to-date issue being broadly studied all over the world. In Russia, salinization processes are predominantly observed in the southern regions, where the main areas of arable land are situated. This research is devoted to mapping of saline lands with the help of satellite data. The study was performed on a 100-hectare plot in the Trans-Ural steppe zone (Republic of Bashkortostan, Russia). A correlation was determined between the level of soil salinity and the main spectral indices associated with Sentinel-2A satellite data. Regression models used 5 salinity indices, vegetation index NDVI, and values of soil conductivity. Linear, quadratic, and logarithmic functions were used. By calculation, the salinity index $5(\mathrm{G} \times \mathrm{R}) / \mathrm{B}$ demonstrated the best correlation values with the salinity level of $\left(\mathrm{R}=0.88, \mathrm{R}^{2}=0.77\right)$ while using the quadratic function. The vegetation index NDVI revealed no correlation, owing to the poor development or dried-up condition of vegetation. On the basis of the developed regression models, salinity maps are drawn, in which the areas of solonchak complexes are defined.
\end{abstract}

\section{Introduction}

Land degradation is one of the most urgent issues worldwide. The Republic of Bashkortostan is one of the top agricultural regions in Russia and has 3.3\% (7326 thousand ha, arable land -3670 thousand ha) of the country's farmland [1]. The region is marked by an increasing manifestation of water and wind erosion on arable land [2]. The Republic also has saline soils on its territory within agricultural lands, that reduce soil capabilities and agricultural potential of the land.

The availability of advanced soil mapping materials is essential for solving applied issues. Yet most of the available map data on soils and their features go back to the last century. Salinization is a dynamic process requiring ongoing monitoring. [3, 4]. In response to growing anthropogenic load and changing climate conditions, data on the spatial distribution of saline soils need to be updated to record them, to customize the land management plan, and to implement subsequent land melioration measure. To this end, it is advisable to use modern methods, such as the application of remote sensing data. Remote methods are faster, more cost-effective, and enable to cover large areas than traditional methods. Increased use

\footnotetext{
${ }^{*}$ Corresponding author: filpip@yandex.ru
} 
of satellite data is supported by improved spatial resolution, a large data set (long-term image archives), a short interval between surveys, and free access to satellite images [5].

The objective of this paper is to analyze the relationship between the soil conductivity and the main spectral indices of salinity in digital mapping of solonchak complexes.

\section{Materials and Methods}

The research was conducted at a location in the Trans-Ural steppe zone in the Khaibullinsky district (Republic of Bashkortostan, Russia). The climate of the region is arid and sharply continental. The study area is 100 ha with elevation differences from 300 to 340 $\mathrm{m}$ above sea level (Fig. 1). On the territory of the plot there is "Mambetovo" reservoir with an area of about 100 hectares, built in 2005. Soils are mainly represented by Calcic Chernozems with low content of total organic matter. Soil-forming sediments are mostly diluvial yellow-brown carbonate clays and heavy loams. Salt-affected soils of the territory (solonetz and solonchak) are of the sulphate, chloride-sulphate and mixed types. Solonetz and solonchak complexes do not make up an independent soil area and are usually found in a complex with saline chernozem soils. The formation of solonetz and solonchak soils is supported by the high content of readily soluble salts from the tertiary seas, as well as the arid climate of the territory $[6,7]$.

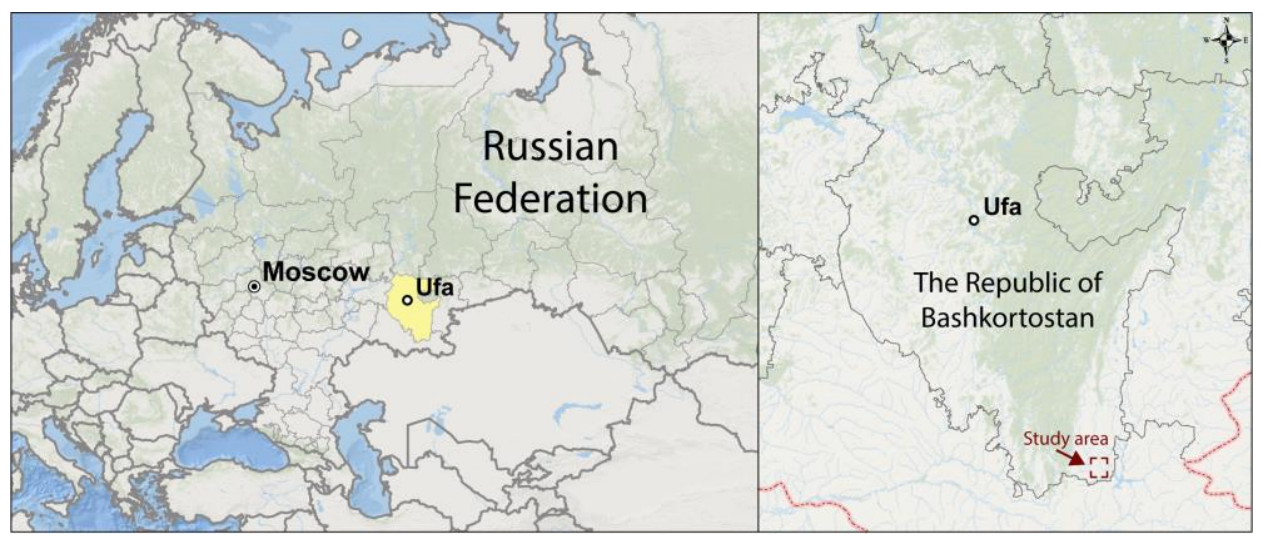

Fig. 1. Location of the study area

In August-September 2018, 25 soil samples were collected on the areas of various types of soil covered with natural vegetation. The degree of soil salinity was defined at the base of conductivity data. Conductivity was measured in a humus-accumulative $0-10 \mathrm{~cm}$ layer under laboratory conditions in accordance with GOST 26423-85 [8].

Data from the Sentinel-2A satellite was used for digital mapping and geomorphometric analysis. The data contains 13 spectral channels with a space resolution from 10 to $60 \mathrm{~m}$. For the best comparison of field and space data, cloud-free images as of September 22, 2018 were chosen. Satellite data processing and creation of graphic materials were done in the QGIS 3.6.0 software. Atmospheric correction was carried out using the "Semi-Automatic Classification Plugin" module. The calculated and used spectral indices based on the combination of channels of the Sentinel-2A satellite are given in table 1.

Table 1. Calculated spectral indices

\begin{tabular}{|l|l|c|l|}
\hline Abbreviation & Spectral index & Equation & Source \\
\hline SI 1 & Index of salinity 1 & $\sqrt{\mathrm{B} \times \mathrm{R}}$ & {$[9]$} \\
\hline SI 2 & Index of salinity 2 & $\sqrt{\mathrm{G} \times \mathrm{R}}$ & {$[9]$} \\
\hline
\end{tabular}




\begin{tabular}{|l|l|c|l|}
\hline SI 3 & Index of salinity 3 & $\sqrt{\mathrm{G}^{2}+\mathrm{R}^{2}+\mathrm{NIR}^{2}}$ & {$[10]$} \\
\hline SI 4 & Index of salinity 4 & $\sqrt{\mathrm{G}^{2}+\mathrm{R}^{2}}$ & {$[10]$} \\
\hline SI 5 & Index of salinity 5 & $\frac{\mathrm{G} \times \mathrm{R}}{\mathrm{B}}$ & {$[11]$} \\
\hline NDVI & $\begin{array}{l}\text { Normalized difference vegetation } \\
\text { index }\end{array}$ & $\frac{\mathrm{NIR}-\mathrm{R}}{\mathrm{NIR}+\mathrm{R}}$ & {$[12]$} \\
\hline
\end{tabular}

B, G, R, NIR - reflection in blue, green, red, and near-infrared channels, respectively

Linear, quadratic, and logarithmic least-squares regressions were applied to identify the relationship between soil conductivity and the values of the calculated indices. Least squares method was successful in the study of saline soils using satellite data $[13,14]$. On the basis of the received regression equations, the areas of saline soils of the total study area were revealed. $\mathrm{R}^{2}$ was calculated to test the accuracy of the regression model of the forecast. Model prediction levels by $R^{2}$ were defined by the following classification: models with $R^{2}<0.4$ have low or extremely low level of forecasting; $0.5<\mathrm{R}^{2}<0.7$ - intermediate level; models with $\mathrm{R}^{2}>0.7$ - high forecasting level [15]. Statistical treatment of data and correlation analysis were carried out using the $\mathrm{R}$ programming language.

\section{Results and Discussion}

Soils conductivity ranged from close to zero to $20 \mathrm{mS} / \mathrm{cm}$, which characterizes the degree of salinity from unsalted to highly saline. Solonchaks are marked by the highest level of salinity due to the salty crust (up to $2-3 \mathrm{~cm}$ thick) on the soil surface. The correlation values between soil conductivity and spectral indices for three different functions are presented in table 2 .

Table 2. The coefficients of correlation $(\mathrm{R})$ and determination $\left(\mathrm{R}^{2}\right)$, respectively

\begin{tabular}{|l|l|l|l|}
\hline Index & Linear & Quadratic & Logarithmic \\
\hline Index of salinity 1 & $0.72 ; 0.53$ & $0.81 ; 0.66$ & $0.75 ; 0.56$ \\
\hline Index of salinity 2 & $0.77 ; 0.59$ & $0.85 ; 0.73$ & $0.79 ; 0.62$ \\
\hline Index of salinity 3 & $0.73 ; 0.53$ & $0.84 ; 0.71$ & $0.79 ; 0.62$ \\
\hline Index of salinity 4 & $0.77 ; 0.59$ & $0.85 ; 0.72$ & $0.79 ; 0.62$ \\
\hline Index of salinity 5 & $0.81 ; 0.66$ & $0.88 ; 0.77$ & $0.81 ; 0.66$ \\
\hline NDVI & $-0.10 ; 0.01$ & $0.28 ; 0.08$ & $0.06 ; 0.01$ \\
\hline
\end{tabular}

According to the results of regression analysis, it was revealed that the maximum values of the correlation and determination coefficients are provided by the salinity index 5 (table $2)$. The best values when using this index are demonstrated for all the studied functions. However, the best results are obtained when using the quadratic function. $\left(\mathrm{R}=0.88, \mathrm{R}^{2}=0.77\right)$ (Fig. 1). In accordance with the classification [15], this index is marked by a high level of forecasting. The index of salinity $5(\mathrm{G} \times \mathrm{R}) / \mathrm{B}$ has visible range channels in its equation (red, green. blue). This index also proved to be useful in studies of soil salinity in Pakistan. $(\mathrm{R}=0.64-0.82)$ [16]. 

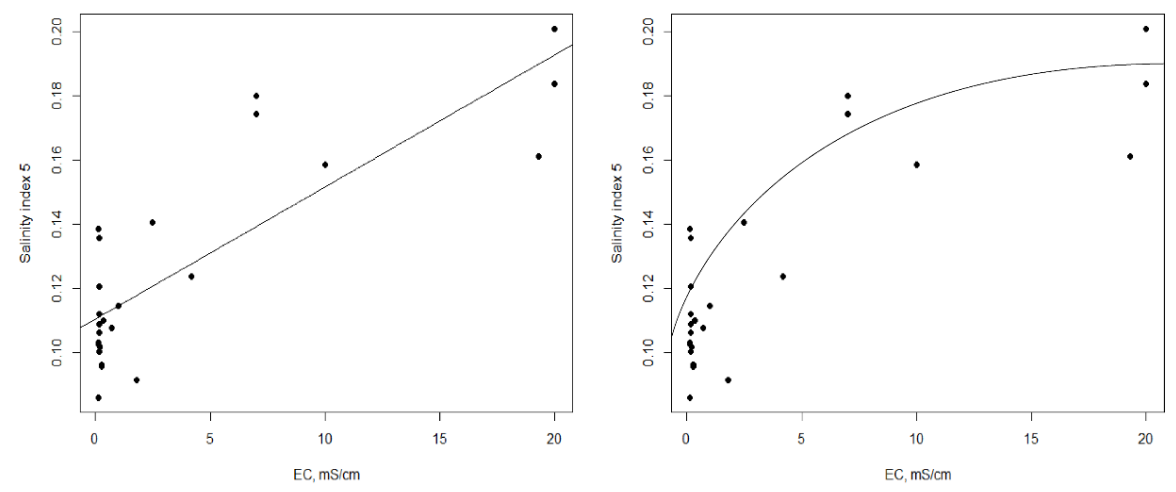

Fig. 2. Graph of linear (left) and quadratic function (right) for index of salinity 5.

In our study, we established that when using linear, quadratic and logarithmic functions, the best results for all indices of salinity are demonstrated by the quadratic function. This is due to the fact that the pixel values of the spectral indices have a limit (up to 0.25) and they are not infinite. For salinity levels, the conductivity can theoretically reach any value. Thus, with increasing salinity (to solonchaks), the values of conductivity reach a plateau, limited to the values of pixels (Fig. 2).

Spectral indices of salinity 1-4 also revealed the highest correlation and determination coefficients for the quadratic function $\left(\mathrm{R}=0.81-0.85, \mathrm{R}^{2}=0.66-0.73\right)$. The salinity index 1 is classified as a model with an average forecast level. Indexes 2-4 are marked by a high level of forecasting.

The vegetation index NDVI revealed no correlation for all three functions, which is due to the weak development or dry condition of vegetation on the area. In researches using the NDVI vegetation index in arid and semi-arid regions, poor results were received by many authors $[10,17,18]$. It was revealed that in the absence of vegetation, there is no correlation between vegetation indices and salinity, while halophytic vegetation shows a poor relationship [3, 14, 19, 20].

On the basis of regression analysis with the use of the salinity index 5 , the equation of the quadratic function is derived $y=-0.0003 x^{2}+0.0099 x+0.105$. With the help of this equation, a map of solonchak complexes was drawn up, which gives an opportunity to calculate their spatial distribution over the entire territory under study (Fig. 3). 


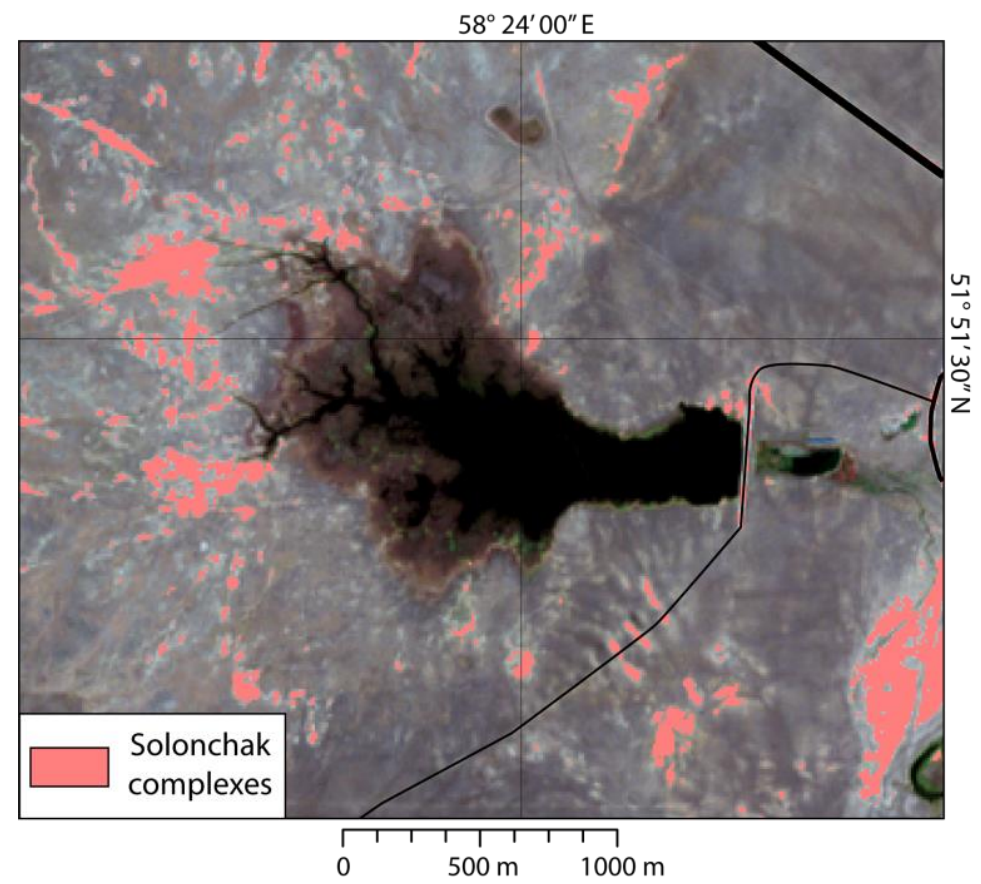

Fig. 3. Map of solonchak complexes distribution

The spatial distribution of solonchak complexes in this region has well-observed patterns. Solonchaks here are hydromorphic soils and their formation is connected with the close groundwater occurrence [7]. In a dry climate with little precipitation, an effusion type of water regime is developed. In this mode, due to active evaporation, readily soluble salts rise to the soil surface. As a result, saline soils in the study area are mainly distributed in low ground features near water bodies: water basins, lakes, and river valleys.

\section{Conclusion}

Growing anthropogenic and exogenous processes necessitate more thorough and permanent monitoring of land. Today, updating and creating relevant soil mapping materials is still an important challenge. Modern map information is essential for recording, monitoring, and studying the spatial distribution of saline soils, both on agricultural and underutilized land.

Follow-up of the utilization of the main spectral salinity indices based on Sentinel-2A data revealed good correlation and determination values. Using the least squares method, the best coefficients are derived utilizing the quadratic function. When mapping saline soils in the study area, it is most suitable to use the salinity index 5, which is based on the visible range channels (red, blue, green). The paper presents the practicability of using satellite data in order to quickly and efficiently correct and update salinity maps. The developed method, with some modifications, may be useful in areas with similar natural conditions.

\section{Acknowledgments}

The reported study was funded by RFBR, project number 19-34-90001 and was performed within the framework of state assignment of the Ministry of Education and Science of the Russian Federation № 075-00326-19-00 on topic № AAAA-A18-118022190102-3. Part of 
the results was obtained using the equipment of the Regional Center for Collective Use "Agidel".

\section{References}

1. Rosreestr. Information on Availability and Distribution of Land in the Russian Federation as of 01.01.2018 (by Subjects of the Russian Federation), Available from: https://rosreestr.ru/site/activity/sostoyanie-zemel-ossii/gosudarstvennyy-natsionalnyydoklad-o-sostoyanii-i-ispolzovanii-zemel-v-rossiyskoy-federatsii/.

2. I.M. Gabbasova, R.R. Suleimanov, I.K. Khabirov, M.A. Komissarov, M. Fruehauf, P. Liebelt, T.T. Garipov, L.V. Sidorova, F.Kh. Khaziev, Eurasian Soil Sci, 49(10), 1204 1210 (2016).

3. E.I. Pankova, Eurasian Soil Sci., 48(2), 115-127 (2015).

4. A.A. Masoud, K. Koike, M.G. Atwia, M.M. El-Horiny, K.S. Gemailm, International Journal of Applied Earth Observation and Geoinformation, 83, 101944 (2019).

5. G.I. Metternichet, J.A. Zinck. Remote Sensing of Environment, 85, 1-20, (2003).

6. P.Y. Bulchuk, Solontsy and saline soils of Bashkir Urals, Tr. Bashkir. research institute of agricultural sciences, 2, 26-52 (1966) (in Russian).

7. P.Y. Bulchuk, Solontsy, saline u solonchak soils. Soils of Bashkiria, 1, 350-383 (1973) (in Russian).

8. GOST 26423-85 soils, Methods for determination of electrical conductivity, $p H$ and density residue of water extracts, (M.: Standardinform, 2011).

9. N.M. Khan, V.V. Rastoskuev, Y. Sato, S. Shiozawa. Agric. Water Manag, 7(1-3), 96109 (2005).

10. A. Douaoui, H. Nicolas, C. Walter, Geoderma, 134(1-2), 217-230 (2006).

11. A. Abbas, S. Khan. Using remote sensing techniques for appraisal of irrigated soil salinity. In: MODSIM 2007: International Congress on Modelling and Simulation: Land, Water and Environmental Management: Integrated Systems for Sustainability, 26322638 (2007).

12. J.W. Rouse, J.R.H. Haas, J.A. Schell, D.W. Deering. Monitoring vegetation systems in the Great Plains with ERTS. In: Proceedings of the 3rd ERTS Symposium. Washington, USA (1974).

13. J. Farifteh, F. Van der Meer, C. Atzberger, E.J.M. Carranza. Remote Sens. Environ. 110(1), 59-78 (2007).

14. J. Wang, J. Ding, D. Yu, X. Ma, Z. Zhang, X. Ge, D. Teng, X. Li, J. Liang, I. Lizaga, X. Chen, L. Yuan, Y. Guo, Geoderma, 353, 172-187, (2019).

15. E. Vaudour, C. Gomez, Y. Fouad, P. Lagacherie, Remote Sensing of Environment, 223, 21-33 (2019).

16. A. Abbas, S. Khan, N. Hussain, M.A. Hanjra, S. Akbar, Phys. Chem. Earth. Parts A/B/C. 55(57), 43-52 (2013).

17. M. Bouaziz, J. Matschullat, R. Gloaguen, Comptes Rendus Geoscience, 343(11-12), 795-803 (2011).

18. J. Peng, H. Xiang, Y. Guo, Z. Shi. Spectrosc. Spectr. Anal., 34(2), 510-514 (2014).

19. Y. Chi, J. Sun, W. Liu, J. Wang, M. Zhao, Ecological Indicators, 107, 105517 (2019).

20. N. Fernández-Buces, C. Siebe, S. Cram, J.L. Palacio, J. Arid Environ, 65(4), 644-667 (2006). 